\title{
Smelling the Wood from the Trees: Non-Linear Parasitoid Responses to Volatile Attractants Produced by Wild and Cultivated Cabbage
}

\author{
Rieta Gols • James M. Bullock • Marcel Dicke • \\ Tibor Bukovinszky • Jeffrey A. Harvey
}

Received: 22 February 2011 /Revised: 20 May 2011 /Accepted: 28 June 2011 /Published online: 12 July 2011

(C) The Author(s) 2011. This article is published with open access at Springerlink.com

\begin{abstract}
Despite a large number of studies on herbivoreinduced plant volatiles (HIPVs), little is known about which specific compounds are used by natural enemies to locate prey- or host- infested plants. In addition, the role of HIPVs in attracting natural enemies has been restricted largely to agricultural systems. Differences in volatile blends emitted by cultivars and plants that originate from wild populations may be attributed to potentially contrasting selection regimes: natural selection among the wild types and artificial selection among cultivars. A more realistic understanding of these interactions in a broader ecological and evolutionary framework should include studies that involve insect herbivores, parasitoids, and wild plants on which they naturally interact in the field. We compared the attractiveness of HIPVs emitted by wild and cultivated cabbage to the parasitoid Cotesia rubecula, and determined the chemical composition of the HIPV blends to elucidate which compounds are involved in parasitoid attraction. Wild and cultivated cabbage differed significantly in their volatile emissions. Cotesia rubecula was differentially attracted to the wild cabbage populations and preferred wild over cultivated cabbage. Isothiocya-
\end{abstract}

\footnotetext{
R. Gols $(\bowtie) \cdot$ M. Dicke

Laboratory of Entomology, Department of Plant Sciences,

Wageningen University,

Wageningen, The Netherlands

e-mail: rieta.gols@wur.nl

J. M. Bullock

Centre for Ecology and Hydrology,

Wallingford, United Kingdom

T. Bukovinszky $\cdot$ J. A. Harvey

Department of Terrestrial Ecology,

Netherlands Institute of Ecology,

Wageningen, The Netherlands
}

nates, which were only emitted by the wild cabbages, may be the key components that explain the preference for wild over cultivated cabbage, whereas terpenes may be important for the differential attraction among the wild populations. Volatile analysis revealed that parasitoid attraction cannot be explained by simple linear relationships. Our results suggest that unraveling which compound(s) are innately attractive to parasitoids of cabbage pests should include wild Brassicaceae.

Key Words Brassica Cotesia rubecula $\cdot$ HIPV. Induction . Jasmonic acid · Terpenes · Terpenoids · Tritrophic interaction $\cdot \mathrm{VOC}$

\section{Introduction}

The study of the factors that underpin rules governing the assembly, structure, and function of ecological communities is complicated by the fact that natural systems generally are characterized by a complex array of structural and chemical heterogeneity. This heterogeneity poses a profound challenge in the exploitation of resources by consumers (herbivores and their natural enemies). Individuals that use information enabling them to exploit resources will enjoy fitness benefits (e.g., Vet and Dicke 1992). Plants are known to emit volatile blends that provide information about the plant's identity, and can provide consumers with reliable information about the presence of a plant that might be a source of food (for herbivores), hosts (for parasitoids), or prey (for predators). However, as volatile signals do not always reveal which prey or host is feeding on the emitting plant and are released in a heterogeneous background, there will be variation in how this information is utilized by organisms throughout the food chain. 
The functional and ecological importance of herbivoreinduced plant volatiles (HIPVs) that are utilized by predators and parasitoids of herbivorous arthropods has received considerable attention over the past 25 years (e.g., Sabelis and Van de Baan 1983; Dicke et al. 1990; Turlings et al. 1995; De Moraes et al. 1998; Dicke and Baldwin 2010). However, despite the large number of papers on this topic, little is known about which specific plant compounds or mixtures of compounds are used by natural enemies to locate prey- or host- infested plants. Many studies with parasitoids of herbivorous arthropods have shown that experienced female wasps, i.e., wasps that have been in contact with hosts or the food plant of the host, are able to discriminate between volatile blends emitted by undamaged and herbivore-damaged plants, and that they prefer the latter (reviewed by Steidle and van Loon 2003; Turlings and Wäckers 2004; Allison and Hare 2009).

Study of the importance of specific HIPVs in natural enemy attraction traditionally has focused on terpenes, fatty acid derivatives (especially those produced by the lipoxygenase pathway), and products from the phenylalanine lyase (PAL) pathway (Ozawa et al. 2000; Schnee et al. 2006; Shiojiri et al. 2006a; Halitschke et al. 2008; Zhang et al. 2009). For example, specific terpenes attract natural enemies of arthropod herbivores when offered individually (Dicke et al. 1990; Rasmann et al. 2005) and are perceived by receptors in the antennae (Smid et al. 2002; Gouinguene et al. 2005). However, Mumm et al. (2008) showed that treatment of cabbage plants with fosmidomycin, an inhibitor of the biosynthesis of certain monoterpenes, did not affect the behavior of Cotesia glomerata. This throws doubt on the role of these monoterpenes as parasitoid attractants in this cabbageparasitoid interaction.

Research on HIPVs and their role in host searching behavior of parasitoids has been driven largely by the potential for insect parasitoids as biological control agents of insect pests. Consequently, these studies often are restricted to cultivated plant species (Berenbaum and Zangerl 2008). However, artificial selection for specific plant traits has often not only changed the appearance of cultivated plants compared to their wild conspecifics, but also their chemistry. For example, wild cabbage Brassica oleracea populations, which grow naturally along the Atlantic coastline of western Europe, contain significantly higher levels of glucosinolates than cultivated cabbage (Harvey et al. 2007; Gols et al. 2008a). Glucosinolates (hereafter GS) are secondary plant compounds that play an important role in defense against insect herbivores and pathogens (Rask et al. 2000). However, the effect of domestication on the volatile profiles of plants has been little studied. For example, it is not known if HIPVs emitted by cultivated plants are similar to those emitted by wild conspecifics or whether natural enemies are equally attracted to HIPVs produced by cultivated and wild conspecifics. Given that insect predators and parasitoids have evolved in natural communities, this is a major gap in our knowledge. Köllner et al. (2008) have shown that a terpene synthase (TPS23) is involved in the production of $(E)$ - $\beta$-caryophyllene, an HIPV that attracts natural enemies of a maize herbivore (Rasmann et al. 2005; Köllner et al. 2008). This gene is expressed in European maize lines as well as in its closest wild relative teosinte, but not in most American cultivated maize varieties (Köllner et al. 2008). This finding suggests that, in addition to plant traits that affect herbivory directly, volatile emissions that can be used by an herbivore's natural enemies also may differ between cultivated and natural conspecific plants.

Here, we compared the chemistry and attractiveness of HIPV blends emitted by plants originating from three wild cabbage (Brassica oleracea L, Brassicaceae, Fig. 1) populations, which differ dramatically in their levels of secondary plant metabolites (Gols et al. 2008b). Consequently, we expected variation in volatile secondary metabolites in response to herbivory, which in turn would differentially attract a parasitoid specialized on hosts feeding on brassicaceous plants. In addition, we compared the attractiveness of HIPV blends emitted by wild and cultivated cabbage to investigate the effect of domestication on parasitoid attraction. Our results are discussed in the context of the phenology of multitrophic interactions in natural communities, an aspect that is often ignored in studies of plant-insect interactions. We argue that studies examining the role of HIPVs on host searching behavior in parasitoids should explore more biologically and ecologically realistic interactions that involve herbivores and their parasitoids on wild food plants, on which these multitrophic interactions initially evolved.

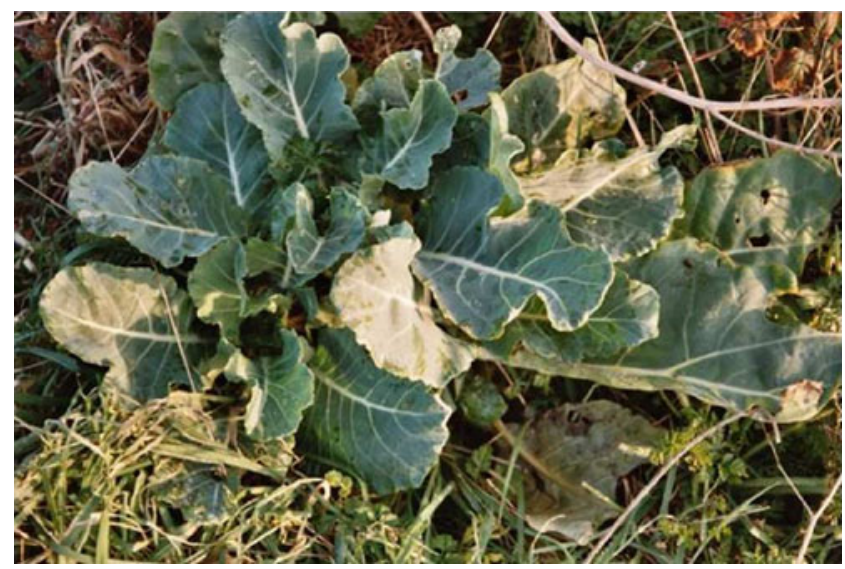

Fig. 1 Wild Brassica oleracea growing naturally along the south coast of Dorset, England 


\section{Methods and Materials}

Plants Seeds of Brassica oleracea were collected from several plants $(>15)$ in three wild cabbage populations growing within $20 \mathrm{~km}$ of each other on chalk cliffs along the south coast of England, near Swanage in Dorset. These wild cabbage populations generally are regarded as the native wild form of cultivated cabbage (Wichmann et al. 2008). The three wild populations were located at sites known as 'Old Harry' ('OH', 50³8'N, $1^{\circ} 55^{\prime} \mathrm{E}$ ), 'Kimmeridge' ('KIM', $50^{\circ}$ $35^{\prime} \mathrm{N}, 2^{\circ} 03^{\prime} \mathrm{E}$ ), and 'Winspit' ('WIN', $50^{\circ} 36^{\prime} \mathrm{N}, 2^{\circ} 07^{\prime} \mathrm{E}$ ). The cultivar used in the experiment was a Brussels sprout variety (B. oleracea gemmifera) cv. Cyrus (CYR hereafter) and differs quantitatively and qualitatively in GS chemistry compared to the three wild cabbage populations (Gols et al. 2008b). Seeds were germinated and seedlings transferred to 1.5 -1 pots filled with potting soil ('Lentse potgrond \#4'). Plants were grown in a greenhouse at $20-30^{\circ} \mathrm{C}, 40-80 \%$ r.h., and a photoperiod of at least $16 \mathrm{hr}$. Plants were watered daily. When plants were 4-wk-old, they were fertilized once a week with Kristallon blauw (N: P: K: micro nutrients as 19: 6: 20: 4) at $2.5 \mathrm{mg} \mathrm{ml}^{-1}$, which was applied to the soil. Plants were 6-wk-old when they were used in experiments.

Insects The herbivore Pieris rapae L (Lepidoptera: Pieridae) and its specialist parasitoid Cotesia rubecula Marshall (Hymenoptera: Braconidae) are native to the Palearctic realm. In the Netherlands, P. rapae has three generations per year. In spring and early summer, the larvae feed mainly on GScontaining wild brassicaceous plant species (Fig. 2), whereas in late summer and autumn, cultivated species also may become important food plants. In this study, the herbivore and the parasitoid were collected originally from a Brussels sprouts field in the vicinity of Wageningen, The Netherlands. Insects were maintained in climate-controlled rooms at 20 $24^{\circ} \mathrm{C}, 60 \%$ r.h., and a photoperiod of $16: 8 \mathrm{~h} \mathrm{~L}$ :D. They were reared on cultivated CYR plants for at least 5 generations. Parasitized hosts were reared on CYR plants until the parasitoids had completed their immature development and egressed from the host. At this point, parasitoid cocoons were collected and transferred to a clean insect cage until adult emergence. Adult wasps were provided with honey as an energy source. In the flight bioassay, we used mated females that were 4-5-d-old and that had had no previous experience with hosts and are referred to as being 'naïve'. Wasps were used only once in the experiments.

To induce the plants, we used first instar (L1) P. rapae larvae, which were obtained from the insect culture.

Attraction of C. Rubecula to Volatiles Emitted by Wild and Cultivated Cabbage Experiment 1 - Herbivore-induced wild cabbage plants. The flight response of female $C$. rubecula to plants infested with $P$. rapae was tested in a tent-like structure $(330 \times 175 \times 280 \mathrm{~cm})$ made out of white nylon sheets, which was placed in a greenhouse $\left(22-25^{\circ} \mathrm{C}\right.$, $50-70 \%$ r.h.). The greenhouse was continuously ventilated, which created a turbulent air current inside the tent. Previous studies have reported that $24 \mathrm{hr}$ of caterpillar feeding results in the production of HIPV (Geervliet et al. 1997; Bruinsma et al. 2009). Each plant was infested with

Fig. 2 Phenology of various wild food plants of Pieris rapae and occurrence of different generations of this herbivore and its specialist parasitoid Cotesia rubecula in the Netherlands. (1) Alliaria petiolata, (2) Brassica napus, (3) Sinapis arvensis (1st generation), (4) Raphanus raphanistrum, (5) Brassica nigra, (6) S. arvensis (2nd generation)

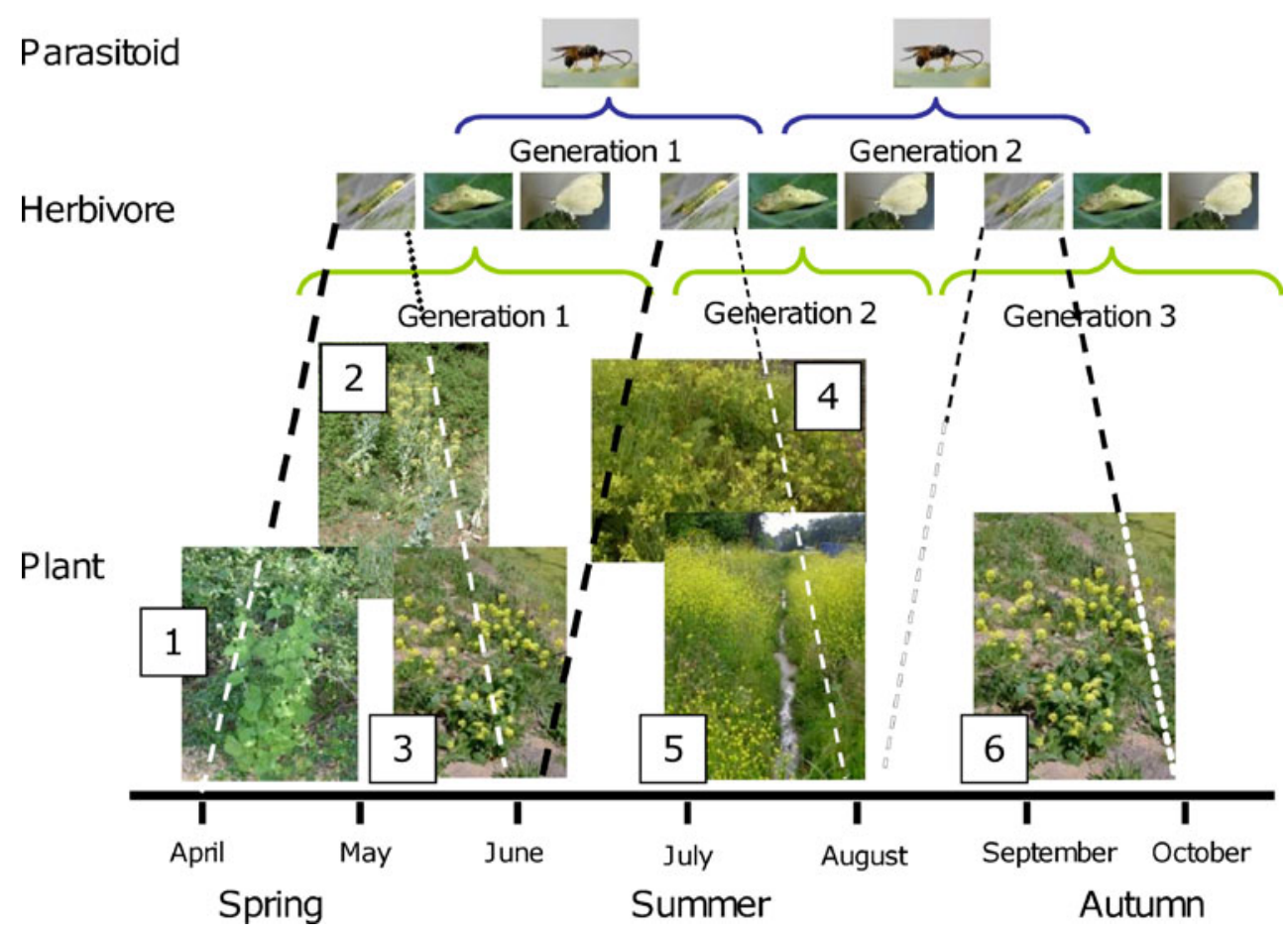


15 L1 P. rapae larvae divided over 3 leaves $20-24 \mathrm{hr}$ prior to the bioassay.

We tested whether female wasps were equally attracted to plants of the 3 wild B. oleracea populations. Three hostinfested plants, one from each cabbage population, were placed in a triangle $1 \mathrm{~m}$ apart. Cotesia rubecula females were collected from the insect cage in glass vials that were closed with cotton wool. These vials with single wasps then were placed in the center of the set-up, and the cotton wool was removed. Since the wasps did not leave the vial immediately, up to 5 vials were placed on the table simultaneously. Wasps were allowed to fly freely within the tent. As soon as a wasp landed on one of the three plants, it was collected, and the plant's identity was recorded. If some of the wasps that were initially released had not alighted on one of the plants within $30 \mathrm{~min}$, they were excluded from the analysis. The response level, i.e., the proportion of wasps that alighted on a plant out of the total of wasps released, varied between 70 and $95 \%$. A total of 30 responsive wasps were recorded for each combination of 3 plants. Based on visual inspection, each plant in a tested combination of plants had received similar amounts of herbivore damage. To control for any bias caused by the position of the plants, individual plants were rotated one position after 10 wasps had landed. The bioassay was repeated 14 times with newly prepared plants over 5 weeks.

Experiment 2 - Herbivore-induced plants: cultivated vs. wild cabbage. Here, we tested whether female $C$. rubecula were equally attracted to the Brussels sprout cultivar (CYR) compared to one of the wild cabbage populations $(\mathrm{OH})$. Plant individuals were infested with $15 \mathrm{~L} 1$ P. rapae larvae divided over 3 leaves $20-24 \mathrm{hr}$ prior to the bioassay. Two host-infested plants, one CYR and one $\mathrm{OH}$ plant were placed at opposite ends of the table (1 m apart) in the tent. Single wasps were released in vials half-way between the two plants. Observations were similar to the previous experiment. A total of 12 responsive wasps were recorded for each combination of two plants. To control for any positional bias, the positions of the plants were switched after 6 wasps had landed on the plants. The bioassay was repeated 15 times with newly prepared plants over 5 weeks.

Experiment 3 - Jasmonic acid (JA)-induced wild cabbage plants. The production of HIPVs is regulated by at least three signal-transduction pathways, the jasmonic acid (JA), the salicylic acid (SA), and the ethylene pathway (reviewed by Arimura et al. 2009). Biosynthesis of volatiles induced by biting-chewing insect herbivores depends mainly on the JA pathway (Reymond et al. 2004; De Vos et al. 2005). Exogenous JA-treatment often is used to mimic the effects of feeding by biting-chewing insects (Dicke et al. 1999; Thaler 1999; Bruinsma et al. 2009; Zhang et al. 2009). Here, we compared JA-treated plants from the 3 wild populations to investigate whether differential attraction to HIPV as observed in experiment 1 can be explained by differences in volatile emissions, whose biosynthesis is dependent on JA signalling.

Plants were sprayed with $15 \mathrm{ml}$ of $1 \mathrm{mM} \mathrm{JA}$ ( \pm jasmonic acid Sigma-Aldrich $>97 \%$ purity) in a $0.2 \%$ Tween 80 (Merck) aqueous solution 20-24 hr prior to experiments. Control plants were sprayed with $15 \mathrm{ml}$ of $0.2 \%$ Tween 80 in water. When plants were treated with JA, few wasps $(<20 \%)$ initiated flying in the set-up that was used in the previous two experiments. Therefore, the flight response of C. rubecula was recorded in a wind tunnel (details in Geervliet et al. 1994), because a previous study showed that the wasps do respond to JA-treated cabbage plants in this device (Bruinsma et al. 2009). The wind tunnel conditions were set at $24 \pm 2{ }^{\circ} \mathrm{C}, 60-70 \%$ r.h., and a wind speed of $20 \mathrm{~cm} \mathrm{~s}^{-1}$. First, we investigated whether JA-treated $\mathrm{OH}$ plants attract more wasps than control $\mathrm{OH}$ plants. To investigate whether plants from the three wild populations are equally attractive to C. rubecula when treated with JA, three pair-wise comparisons were made, OH-WIN, OHKIM, and WIN-KIM, as the wind tunnel only allows for dual-choice comparisons. Up to 5 vials with single wasps were placed in a horizontal glass cylinder on a $10-\mathrm{cm}$ high socket positioned $60 \mathrm{~cm}$ downwind from the two plants. Recordings were similar to the previous experiments. Wasps that had not alighted on one of the plants within $15 \mathrm{~min}$ were removed and excluded from the analysis. Additional wasps were released until a total of 12 wasps had made a choice. The response level of the females in the wind tunnel varied between 60 and $90 \%$. The position of the plants was switched after 6 wasps had made a choice. Each plant combination was tested eight times with newly prepared plants over 6 weeks.

Headspace Analysis of Herbivore Infested Plants: Collection of Volatiles Volatiles were collected from individual host-infested plants $(N=5$ or 6$)$ from each of the four $B$. oleracea lines used in the bioassays. Plants were induced similarly as in the flight bioassays, i.e., plant individuals were infested with 15 L1 P. rapae larvae divided over 3 leaves $20-24 \mathrm{hr}$ prior to volatile collection An entire hostinfested plant, including soil, which was contained in aluminum foil, was transferred to a clean 35-1 glass collection container. Pressurized air was filtered over silica gel, molecular sieves (4 A, Sigma, St Louis MO, USA) and activated charcoal before entering the sampling container. Prior to sampling, the container was purged for $1 \mathrm{hr}$ at $10 \mathrm{l} /$ h. Subsequently, headspace volatiles were trapped on $90 \mathrm{mg}$ Tenax TA for $4 \mathrm{hr}$ at a flow of approximately $40 \mathrm{ml} / \mathrm{min}$. Volatiles were also collected $(N=2)$ from a collection container containing a piece of aluminum foil with water. Volatile compounds detected in these control samples were excluded from the data obtained for the plant samples. 
Collected volatiles were released from the Tenax traps by heating in a thermodesorption cold trap unit (Markes, UK) at $200^{\circ} \mathrm{C}$ for $10 \mathrm{~min}$ and flushing with a He flow of $30 \mathrm{ml} /$ min. Released compounds were cryofocused in a coldtrap at a temperature of $-10^{\circ} \mathrm{C}$. Volatiles were injected in splitless mode into the RTX-5 Silms GC column (Restec, $30 \mathrm{~m} \times 0.32 \mathrm{~mm}$ ID, $0.33 \mu \mathrm{m}$ film thickness) by heating of the cold trap to $270^{\circ} \mathrm{C}$. After an initial column temperature of $40^{\circ} \mathrm{C}$ for $2 \mathrm{~min}$, the temperature was raised to $90^{\circ} \mathrm{C}$ at $3^{\circ} \mathrm{C} /$ $\min$, then to $165^{\circ} \mathrm{C}$ at $2^{\circ} \mathrm{C} / \mathrm{min}$, and subsequently to $250^{\circ} \mathrm{C}$ at $15^{\circ} \mathrm{C} / \mathrm{min}$. The column was directly coupled to the ion source of a Finnigan quadrupole mass spectrometer, which was operating in the $70 \mathrm{eV}$ EI ionization mode and scanning from mass 33 to 300 at $3 \mathrm{scans} / \mathrm{sec}$. Collected volatiles were separated and identified using GS/MS (gas chromatography combined with mass spectrometry). Compounds were tentatively identified by comparison of the mass spectra with those in the NIST 2002 (version 2a) and Wiley 7 edition spectral libraries and by checking the retention indices. For identification and quantification, we used AMDIS version 2.1 (Automated Mass spectral Deconvolution \& Identification Software). Compounds were quantified by measuring peak areas of the total ion fractions of the integrated signal. Peak areas were divided by above-ground fresh weight of plant tissue, which was determined immediately after trapping.

Statistical Analysis To determine whether C. rubecula females were differentially attracted to the three wild cabbage populations, we conducted a $G$-test for independence on wasp counts in the replicated three-way choice bioassays. The results for the replicate tests were homogeneous, so a G-test (goodness of fit) was conducted on the pooled data $\left(\mathrm{H}_{0}=\right.$ the three populations are equally attractive). A similar approach was used for the dual choice bioassays.

First, we determined whether population preferences could be explained by abundance patterns of individual volatile compounds. Each of the volatiles produced by the three wild populations was subjected to Kruskal-Wallis non-parametric one-way ANOVA. For the CYR-OH comparison, Mann-Whitney $U$ tests were used. For each of the compounds for which the population effect was significant, we determined whether the emissions quantities ranked according to the landing preference. In a second approach, we used multivariate statistics (Principle Components Analysis = PCA) to reveal: (1) which volatile compounds are important for the separation of the three wild cabbage populations; (2) which are important for the separation of the $\mathrm{OH}$ and WIN plants; and (3) which are important for the separation of the wild $\mathrm{OH}$ and cultivated CYR plants. PLSDA (Projection to Latent Structures Discriminant Analysis) is a projection method that separates groups of observations by rotating the PCA's such that a maximum separation among classes, here $B$. oleracea populations, is obtained (Eriksson et al. 2006). To achieve this, a Y-data matrix of dummy variables is included, which assigns a sample to its respective class, here population. The PLS-DA extension of the SIMCA P+ 12.0 software program (Umetrics $\mathrm{AB}$, Umeå, Sweden) used for this analysis approximates the point 'swarm' in $\mathrm{X}$ (matrix with volatile compounds) and $\mathrm{Y}$ in PLS components in such a way that maximum covariation between the components in $\mathrm{X}$ and $\mathrm{Y}$ is achieved. The results of the analysis are visualized in score plots, which reveal the sample structure according to the model components, and loading plots, which display the contribution of the variables to these components, as well as the relationships among the variables. The program's cross validation procedure evaluates the significance of each additional component (starting with none) by comparing the goodness of fit $\left(R^{2}\right)$ and the predictive value $\left(Q^{2}\right)$ of the extended model with that of the reduced model. In a second PLS-DA analysis, those compounds were eliminated that contributed little to the separation of the samples belonging to different populations based on the variable importance on projection values (VIP values). Variables with VIP values greater than 1 are most influential to the model (Eriksson et al. 2006). Per sample, amounts of the individual volatile compounds were measured as peak areas divided by fresh mass (g) of aboveground plant tissues. In the analysis, those volatile compounds were included that were present in at least three of the samples in one of the populations. Based on their biosynthetic pathways, the substances found in volatile plant emissions in response to herbivory can be classified into terpenes, fatty acid derivatives, phenylpropanoids, benzenoids, and various nitrogen and sulfur containing products (Dudareva et al. 2004). Here, we also included the total amounts of alcohols, esters, aldehydes, ketones, sulfides, terpenes, and nitrogencontaining volatiles, as variables in the analyses. Data were log-transformed, mean-centered, and scaled to unit variance before they were subjected to the analysis.

\section{Results}

Attraction of C. rubecula to Caterpillar-Induced Volatiles Emitted by Wild and Cultivated Cabbage Plants (Experiments 1 and 2) The results for the flight bioassays in experiment 1 and 2 were homogenous (wild cabbage populations: $\chi 2=25.2, d f=26, P=0.51$; OH vs. CYR plants: $\chi^{2}=0.94, d f=14, P=0.95$ ). Cotesia rubecula females were differentially attracted to the plants of the three wild populations ( $\chi 2=7.04, d f=2, P=0.03$, Fig. 3 ), and $\mathrm{OH}$ plants were significantly more attractive to the parasitoids than 


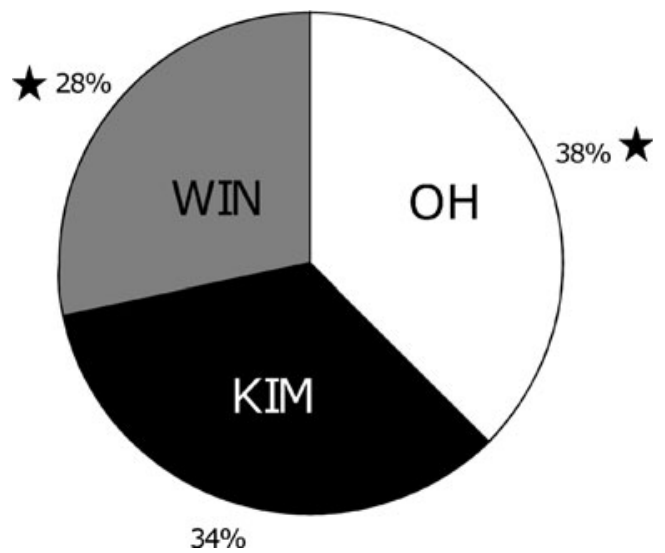

Fig. 3 Landing preference of Cotesia rubecula in a three-way comparison of wild host-infested Brassica oleracea plants originating from three wild populations (OH, KIM, and WIN) in Dorset, UK. Pie parts represent the average percentages of 14 bioassays performed in a tent set-up. In each bioassay 30 landing preferences were recorded (in total 420 wasps were released). The asterisks indicate populations for which the wasp preference was higher or lower than the expected preference of $1 / 3$ (G-test for goodness of fit)

WIN plants (Fig. 3). Despite their rearing history on CYR plants, $C$. rubecula females preferred to alight on $\mathrm{OH}$ over CYR plants $(\chi 2=9.67, d f=1, P=0.002$, Fig. 4 a)

Attraction of C. rubecula to Volatiles Induced by JA Treatment (Experiment 3) To investigate whether volatiles whose biosynthesis is dependent on the JA signaling pathway are involved in the differential attraction of $C$. rubecula, plants from the three wild populations were treated with JA. In the first set of experiments, $\mathrm{OH}$ plants treated with $\mathrm{JA}$ were more attractive than $\mathrm{OH}$ plants treated with control solution $(\chi 2=6.06, d f=1, P=0.02$, Fig. $4 \mathrm{~b})$. However, parasitoids did not discriminate between JAtreated plants of the three populations when offered pairwise combinations (Fig. 4b).

Headspace Analysis of Herbivore Infested Plants Fortynine different compounds were detected in at least three samples of one plant population (Table 1). Interestingly, volatile breakdown products of GS (but-3-enyl isothiocyanate and prop-2-enyl isothiocyanate) were produced only by wild cabbage plants. Volatile quantities of 13 compounds, i.e., but-3-enyl isothiocyanate and 12 terpenes, were significantly different when the three wild populations were compared using the Kruskal Wallis test. However, none of their emission quantities ranked $\mathrm{OH}>\mathrm{KIM}>\mathrm{WIN}$, i. e., the preference ranking of C. rubecula. Emissions of $\delta$-3carene ranked WIN $>\mathrm{KIM}>\mathrm{OH}$, suggesting that this compound might repel $C$. rubecula. A PLS-DA including volatiles emitted by the three wild cabbages that significantly explained some of the variance, i.e., those compounds that had VIP values $>1$ ( 23 compounds), resulted in a model with three significant principal components (PC). The first PC separated KIM samples from the $\mathrm{OH}$ and WIN samples, whereas the second $\mathrm{PC}$ further separated the $\mathrm{OH}$ and the WIN samples (Fig. 5). This means that the volatile blends emitted by $\mathrm{OH}$ and WIN plants were more similar to each other than to the blends emitted by KIM plants. The KIM plants were characterized by relatively high emissions of the alcohols 3-pentanol and (Z)-3-hexen-1-ol and low amounts of the volatiles located at the right hand side in
Fig. 4 Landing preference of Cotesia rubecula in a two-way comparison with cabbage plants. a Comparison of a host-infested cultivated (CYR) and wild $(\mathrm{OH})$ plant and b pair-wise comparisons of JA-treated $(1 \mathrm{mM})$ plants of the three wild Brassica oleracea populations, $\mathrm{OH}$, KIM, and WIN (top three bars) and $\mathrm{OH}$ plants treated with JA or control solution (bottom bar). Experiments were performed in a wind tunnel. Significance levels indicate whether the preference for either plant offered in the bioassay is significantly different from a 50-50 distribution (G-tests for goodness of fit, NS = not significant). Numbers in brackets indicate the number of replicates. In each replicate 12 responding wasps were recorded

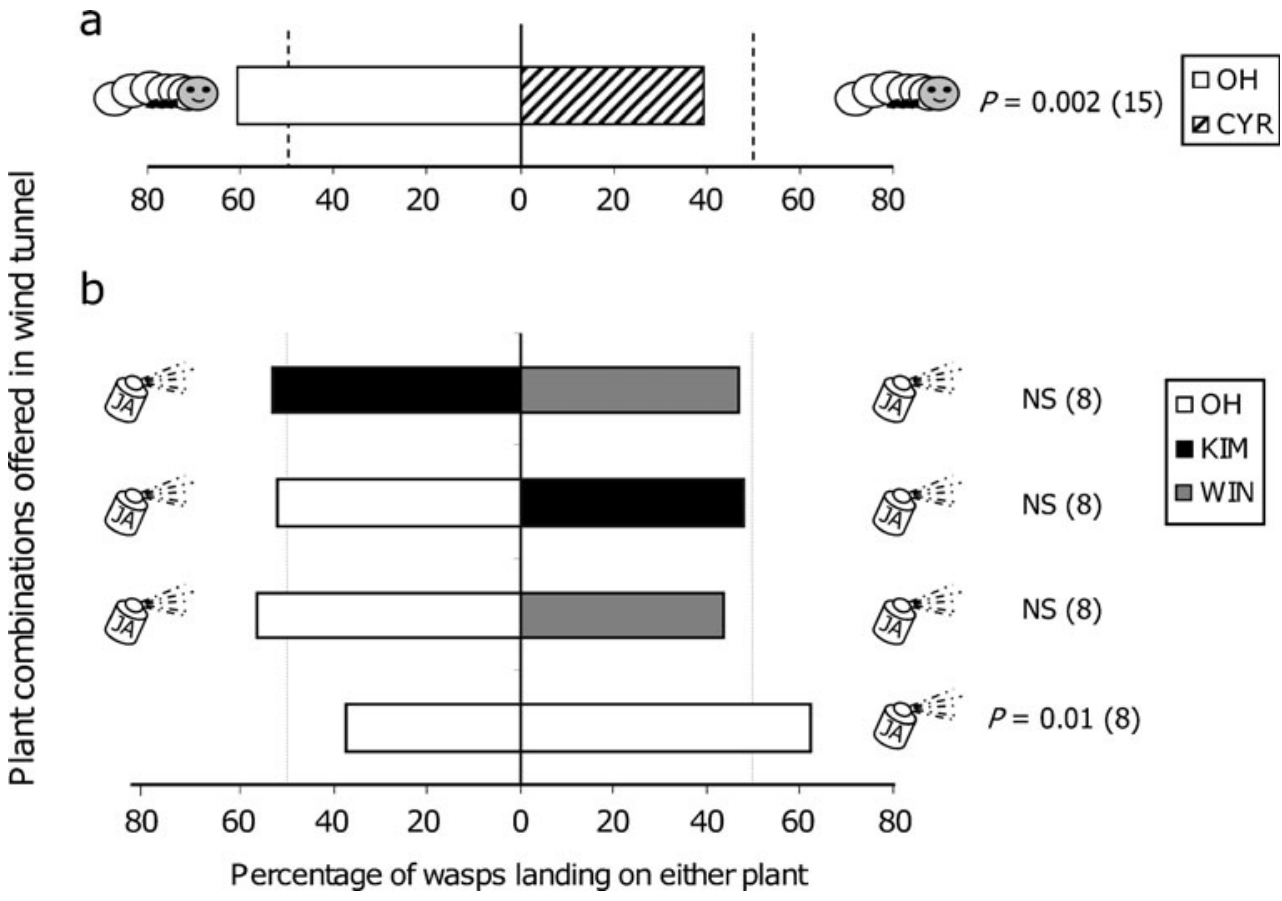


Table 1 Vblatile emissions ${ }^{\text {a }}$ by plants originating from three wild cabbage (Brassica oleracea) populations (OH, KIM and WIN) and a brussels sprout cultivar (CYR) in response to Pieris rapae caterpillar feeding

\begin{tabular}{|c|c|c|c|c|c|}
\hline $\mathrm{ID}^{\mathrm{b}}$ & $\begin{array}{l}\text { Population } \rightarrow \\
\text { Compound names } \downarrow\end{array}$ & $\begin{array}{l}\mathrm{OH} \\
(N=6)\end{array}$ & $\begin{array}{l}\text { KIM } \\
(N=6)\end{array}$ & $\begin{array}{l}\text { WIN } \\
(N=5)\end{array}$ & $\begin{array}{l}\text { CYR } \\
(N=5)\end{array}$ \\
\hline & (Alcohols) & & & & \\
\hline 1 & 1-Penten-3-ol & $4.3 \pm 0.9$ & $13.0 \pm 4.4$ & $6.6 \pm 2.0$ & $19.7 \pm 4.4$ \\
\hline 2 & 3-Pentanol & $0.5 \pm 0.2^{5 !}$ & $1.9 \pm 0.7$ & $0.6 \pm 0.3^{4}$ & $16.3 \pm 4.4$ \\
\hline 3 & 1-Pentanol & - & - & - & $0.6 \pm 0.2$ \\
\hline 4 & (Z)-2-Penten-1-ol & - & - & - & $1.4+0.7$ \\
\hline 5 & (Z)-3-Hexen-1-ol & $0.9 \pm 0.2$ & $4.1 \pm 2.4$ & $1.3 \pm 0.5$ & $8.0 \pm 3.6$ \\
\hline 6 & 1-Hexanol & $0.12 \pm 0.08^{2}$ & $0.04 \pm 0.04^{1}$ & $0.5 \pm 0.2^{4}$ & $1.8 \pm 1.3$ \\
\hline \multirow[t]{3}{*}{7} & 3-Heptanol & - & $0.04 \pm 0.04^{1}$ & - & $2.3 \pm 0.5$ \\
\hline & (Esters) & & & & \\
\hline & Butyl acetate & $1.1 \pm 0.2$ & $0.8 \pm 0.2$ & $0.7 \pm 0.1$ & $0.5 \pm 0.2$ \\
\hline 8 & 3-Methyl-1-butyl acetate & - & - & - & $0.2 \pm 0.1$ \\
\hline \multirow[t]{2}{*}{9} & (Z)-2-Penten-1-yl acetate & $0.23 \pm 0.06$ & $1.5 \pm 0.7^{5}$ & $0.4 \pm 0.1$ & $12.1 \pm 4.0$ \\
\hline & (Z)-3-Hexen-1-yl acetate & $18.2 \pm 6.1$ & $38.2 \pm 17.7$ & $21.2 \pm 11.4$ & $37.8 \pm 7.0$ \\
\hline 10 & Hexyl acetate & $1.0 \pm 0.4^{5}$ & $2.5 \pm 1.8^{5}$ & $0.4 \pm 0.2^{4}$ & $7.4 \pm 3.6$ \\
\hline \multirow[t]{2}{*}{11} & (Z)-3-Hexen-1-yl-pronanoate & - & - & - & $0.4 \pm 0.3$ \\
\hline & Heptyl acetate & $0.06 \pm 0.04^{2}$ & - & $0.03 \pm 0.03^{1}$ & $0.3 \pm 0.2^{4}$ \\
\hline \multirow[t]{4}{*}{12} & 2-Ethylhexyl acetate & $0.5 \pm 0.2^{4}$ & $0.7 \pm 0.3^{4}$ & $0.7 \pm 0.3^{4}$ & $3.7 \pm 0.5$ \\
\hline & Methyl salicylate & $0.03 \pm 0.02^{2}$ & $0.02 \pm 0.02^{1}$ & $0.02 \pm 0.02^{1}$ & $7.2 \pm 6.9^{4}$ \\
\hline & (Nitrogen containing compounds) & & & & \\
\hline & Methyl thiocyanate & $1.6 \pm 0.8$ & $0.8 \pm 0.1$ & $0.9 \pm 0.3$ & $0.4 \pm 0.1$ \\
\hline 13 & 3-Methylbutanenitrile & $0.05 \pm 0.05^{1}$ & - & $2.0 \pm 1.0^{4}$ & $4.7 \pm 3.6$ \\
\hline 14 & 3-Methyl-3-butenenitrile & $0.5 \pm 0.1^{5}$ & $0.8 \pm 0.3^{4}$ & $0.9 \pm 0.2$ & - \\
\hline 15 & Prop-2-enyl isothiocyanate & $0.3 \pm 0.2^{2}$ & $0.2 \pm 0.1^{5}$ & $0.8 \pm 0.3^{4}$ & - \\
\hline \multirow[t]{2}{*}{16} & But-3-enyl isothiocyanate* & $1.8 \pm 1.1^{5}$ & $0.5 \pm 0.4^{2}$ & $2.5 \pm 0.2$ & - \\
\hline & (Ketones) & & & & \\
\hline 17 & 3-Pentanone & $3.5 \pm 1.3$ & $11.0 \pm 4.1$ & $7.5 \pm 2.6$ & $30.0 \pm 4.9$ \\
\hline 18 & 3-Hexanone & - & - & - & $3.5 \pm 0.8$ \\
\hline 19 & 2-Hexanone & $0.41 \pm 0.06$ & $0.6 \pm 0.1$ & $1.6 \pm 1.0$ & $13.8 \pm 3.1$ \\
\hline 20 & 3-Heptanone & $0.58 \pm 0.09$ & $1.0 \pm 0.2$ & $1.2 \pm 0.5$ & $7.9 \pm 1.8$ \\
\hline \multirow[t]{5}{*}{21} & 2-Heptanone & $0.17 \pm 0.04^{5}$ & $0.30 \pm 0.06^{5}$ & $0.4 \pm 0.2$ & $1.6 \pm 0.3$ \\
\hline & (Sulfides) & & & & \\
\hline & Dimethyldisulfide & $1.7 \pm 0.2$ & $2.5 \pm 0.9$ & $1.8 \pm 0.3$ & $2.4 \pm 1.3$ \\
\hline & Dimethyltrisulfide & $0.49 \pm 0.07$ & $0.6 \pm 0.1$ & $0.52 \pm 0.09$ & $0.5 \pm 0.2$ \\
\hline & (Terpenes) & & & & \\
\hline 22 & $\alpha$-Thujene* & $18.7 \pm 3.6$ & $2.7 \pm 1.0^{5}$ & $14.3 \pm 3.8$ & $29.8 \pm 8.0$ \\
\hline \multirow[t]{2}{*}{23} & $\alpha$-Pinene* & $11.2 \pm 2.6$ & $2.5 \pm 0.5$ & $8.5 \pm 2.1$ & $12.0 \pm 3.2$ \\
\hline & Thuja-2-4(10)diene & $0.05 \pm 0.02^{5}$ & $0.09 \pm 0.02$ & $0.06 \pm 0.02^{4}$ & $0.08 \pm 0.02$ \\
\hline 24 & Sabinene* & $54.6 \pm 9.0$ & $9.6 \pm 3.5$ & $50.4 \pm 13.3$ & $49.2 \pm 6.2$ \\
\hline 25 & 2- $\beta$-Pinene* & $5.6 \pm 1.3$ & $1.2 \pm 0.3$ & $4.5 \pm 1.1$ & $9.8 \pm 3.5$ \\
\hline 26 & $\beta$-Myrcene* & $14.8 \pm 3.2$ & $2.6 \pm 0.9^{5}$ & $11.0 \pm 2.7$ & $25.6 \pm 7.3$ \\
\hline 27 & 1-Phellandrene & $0.03 \pm 0.02^{2}$ & $0.2 \pm 0.2^{1}$ & - & $0.4 \pm 0.2$ \\
\hline 28 & $\delta$-3-Carene* & $0.09 \pm 0.04$ & $0.11 \pm 0.02$ & $0.4 \pm 0.1$ & $0.2 \pm 0.1$ \\
\hline 29 & $\alpha$-Terpinene & $0.17 \pm 0.06$ & $0.02 \pm 0.01^{2}$ & $0.09 \pm 0.03$ & $1.1 \pm 0.6$ \\
\hline 30 & Limonene & $24.5 \pm 6.1$ & $5.9 \pm 1.7$ & $25.1 \pm 6.6$ & $27.3 \pm 2.8$ \\
\hline 31 & 1,8-Cineole* & $8.1 \pm 2.1$ & $0.7 \pm 0.3$ & $4.5 \pm 1.1$ & $14.2 \pm 4.3$ \\
\hline 32 & Unknown terpenoid* & $0.04 \pm 0.02^{4}$ & - & $0.01 \pm 0.01^{1}$ & $0.2 \pm 0.1$ \\
\hline 33 & (E)- $\beta$-Ocimene* & $0.32 \pm 0.07$ & $0.04 \pm 0.03^{2}$ & $0.09 \pm 0.04^{3}$ & $1.0 \pm 0.8$ \\
\hline
\end{tabular}


Table 1 (continued)

\begin{tabular}{|c|c|c|c|c|c|}
\hline $\mathrm{ID}^{\mathrm{b}}$ & $\begin{array}{l}\text { Population } \rightarrow \\
\text { Compound names } \downarrow\end{array}$ & $\begin{array}{l}\mathrm{OH} \\
(N=6)\end{array}$ & $\begin{array}{l}\text { KIM } \\
(N=6)\end{array}$ & $\begin{array}{l}\text { WIN } \\
(N=5)\end{array}$ & $\begin{array}{l}\text { CYR } \\
(N=5)\end{array}$ \\
\hline 34 & $\gamma$-Terpinene* & $0.35 \pm 0.10$ & $0.06 \pm 0.03^{3}$ & $0.20 \pm 0.08^{4}$ & $2.4 \pm 1.3$ \\
\hline 35 & Trans-sabinene hydrate* & $0.42 \pm 0.09$ & $0.04 \pm 0.02^{2}$ & $0.3 \pm 0.1$ & $2.2 \pm 1.4$ \\
\hline 36 & $\alpha$-Terpinonelene* & $0.26 \pm 0.06$ & $0.04 \pm 0.01^{5}$ & $0.20 \pm 0.06$ & $1.2 \pm 0.6$ \\
\hline 37 & cis-Sabinene-hydrate & $0.03 \pm 0.03^{1}$ & - & $0.03 \pm 03^{1}$ & $0.5 \pm 0.3$ \\
\hline 38 & $\mathrm{DMNT}^{\mathrm{c}}$ & $3.0 \pm 0.9$ & $2.3 \pm 2.0^{3}$ & $0.9 \pm 0.6^{2}$ & $1.1 \pm 0.8$ \\
\hline 39 & Terpinen-4-ol & - & - & - & $0.2 \pm 0.1^{4}$ \\
\hline \multirow[t]{2}{*}{40} & $\alpha$-Terpineol & $0.12 \pm 0.07^{3}$ & $0.01 \pm 0.01^{1}$ & $0.02 \pm 0.02^{1}$ & $0.2 \pm 0.1$ \\
\hline & $(E, E)-\alpha$-Farnesene & $0.15 \pm 0.07^{4}$ & $0.25 \pm 0.05$ & $0.38 \pm 0.02^{3}$ & $0.02 \pm 0.02^{1}$ \\
\hline 41 & Terpenes* & $142 \pm 28$ & $28.2 \pm 9.4$ & $121 \pm 31$ & $178 \pm 39$ \\
\hline 42 & Alcohols & $5.9 \pm 1.3$ & $19.1 \pm 7.4$ & $9.0 \pm 2.8$ & $50.1 \pm 13.7$ \\
\hline 43 & Esters & $21.2 \pm 6.8$ & $44.0 \pm 20.1$ & $24.0 \pm 11.6$ & $71.3 \pm 16.9$ \\
\hline 44 & N-containing compounds* & $4.1 \pm 1.3$ & $2.3 \pm 0.5$ & $7.1 \pm 1.1$ & $5.1 \pm 3.7$ \\
\hline \multirow[t]{3}{*}{45} & Ketones & $4.5 \pm 1.3$ & $12.6 \pm 4.1$ & $10.3 \pm 3.8$ & $55.2 \pm 9.2$ \\
\hline & Sulfides & $2.1 \pm 0.3$ & $3.1 \pm 1.0$ & $2.4 \pm 0.4$ & $2.9 \pm 1.5$ \\
\hline & Total & $180 \pm 34$ & $109 \pm 40$ & $174 \pm 46$ & $363 \pm 71$ \\
\hline
\end{tabular}

${ }^{a}$ Volatile emissions are given as mean peak area $\pm \mathrm{SE} / \mathrm{g}$ fresh weight of foliage with the number of samples between brackets

${ }^{\mathrm{b}}$ ID corresponds with the numbers presented in Fig. 5, 6 and 7

${ }^{\mathrm{c}} \mathrm{DMNT}=(E)$-3,4,8-dimethyl-1,3,7-nonatriene

!Numbers in superscript following emission quantities give the number of samples in which the compound was detected, if it was not found in all the samples of that population

${ }^{*}$ Compounds with asterisks indicate significant differences in emission quantities among the three wild populations (Kruskal-Wallis one-way ANOVA)

Fig. 5. A PLS-DA performed on WIN and OH samples, which were the least and most attractive populations, respectively, in the flight bioassay, resulted in a model with one significant PC (Fig. 6). From the 16 compounds that were included in the analysis, 3-methyl-butanenitrile and $\delta$ 3 -carene (both produced in higher amounts by WIN plants, Mann-Whitney $U$ tests, $P=0.052$ and $P<0.05$, respectively) and $(E)$ - $\beta$-ocimene and $(E)$-3,4,8-dimethyl-1,3,7-nonatriene $(=\mathrm{DMNT}$ ) (both produced in slightly higher amounts by $\mathrm{OH}$ plants, Mann-Whitney $U$ tests, both $P=0.052$ ) contributed the most to the separation of the odor blends. Emission of the other 12 compounds did not differ significantly between the two populations. Similarly, CYR and $\mathrm{OH}$ volatiles were compared resulting in a model with two significant PC's (Fig. 7). Emissions of the 26 compounds that were included in the model differed significantly (all $P$ values $\leq 0.05$ Mann-Whitney $U$ tests) between $\mathrm{OH}$ and CYR plants. The only two compounds that contributed to the separation of the samples and were produced in higher amounts by $\mathrm{OH}$ plants were the $\mathrm{N}$-containing volatiles, 3methyl-3-butenenitrile and but-3-enyl isothiocyanate. However, when $\mathrm{OH}$ and WIN plants were compared, quantities of these compounds tended to be higher in WIN than in $\mathrm{OH}$ plants (Mann-Whitney $U$ test: 3-methyl-3-butenenitrile, $P=$ 0.052 ; but-3-enyl isothiocyanate and $P=0.13$ ). Quantities of
(E)- $\beta$-ocimene and DMNT, which matched the parasitoid preference ranking $\mathrm{OH}>\mathrm{WIN}$, did not significantly differ between $\mathrm{OH}$ and CYR plants $(P=0.79$ and $P=0.25$, respectively). Thus, emissions of these four compounds do not reflect parasitoid preference.

\section{Discussion}

This study showed that there were significant differences between the volatile profiles of the wild $B$. oleracea populations and the cultivar, as well as among the wild populations of this plant. Furthermore, the parasitoid $C$. rubecula was differentially attracted to $B$. oleracea plants from three different wild populations of this species even though they grow less than $20 \mathrm{~km}$ from each other in nature. Cotesia rubecula also was more attracted to $\mathrm{OH}$ plants than to the Brussels sprout variety on which the parasitoid had been reared for many generations. However, C. rubecula did not discriminate between volatile blends emitted by the three wild $B$. oleracea populations when treated with JA, a plant hormone that is the key component produced in the lipoxygenase pathway, and which is often used to mimic insect herbivory (Dicke et al. 1999; Thaler 1999; Bruinsma 
Fig. 5 PLS-DA (Projection to Latent Structures Discriminant Analysis) of quantities of volatile compounds produced by wild Brassica oleracea plants originating from three wild populations (OH, KIM, and WIN) in Dorset, UK, in response to Pieris rapae feeding. The score plot a visualizes the structure of the samples according to the first two PLS components with the explained variance in brackets. The ellipse in the score plot defines the Hotelling's $\mathrm{T}^{2}$ confidence region, which is a multivariate generalization of Student's $t$-test and provides a $95 \%$ confidence interval for the observations. The loading plot $\mathbf{b}$ define the orientation of the PLS planes with the original variables in the $\mathrm{X}$ (volatile variables) and Y space ('class' variables), respectively. They reveal the magnitude and direction of correlation of the original variables with the first two PLS components. The PLS-DA resulted in a model with 3 significant components: $R^{2} \mathrm{X}=$ $0.77, R^{2} \mathrm{Y}=0.82 Q^{2}=0.67$. For compound identity see Table 1 a

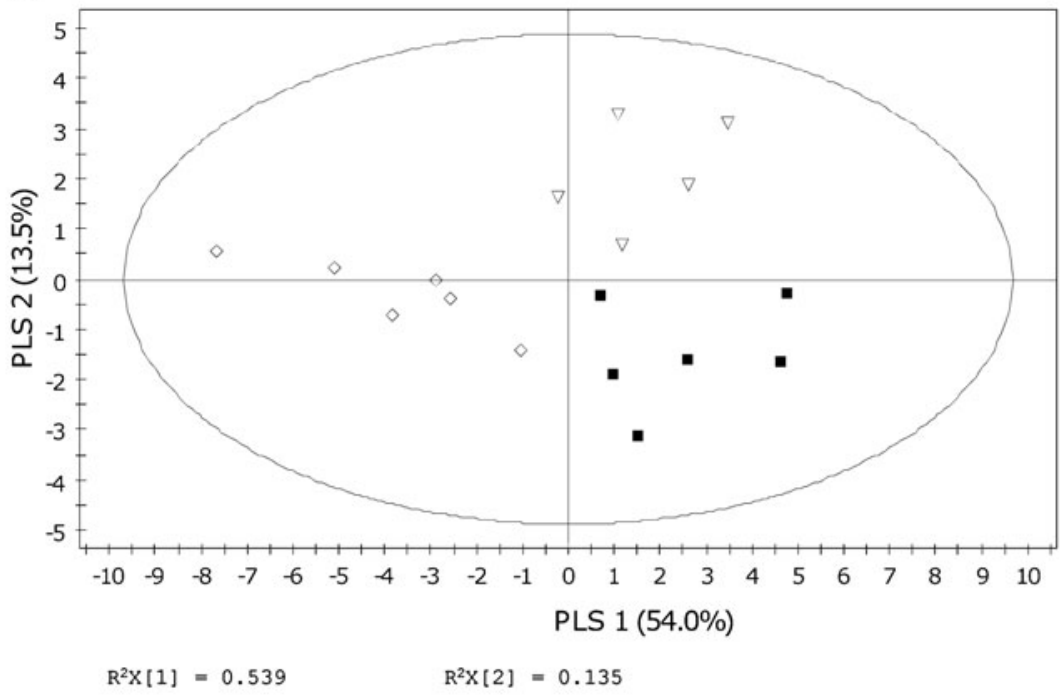

- $\mathrm{OH}$

$\diamond \mathrm{KIM}$

$\nabla$ WIN

b

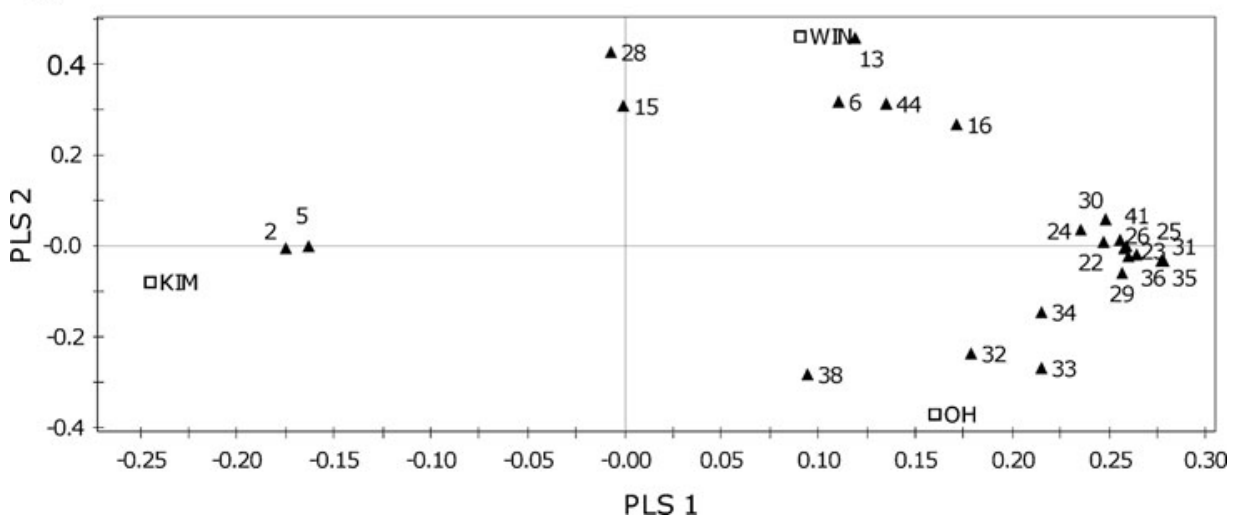

et al. 2009; Zhang et al. 2009). Although each population produced distinctive profiles of volatile chemicals, these did not simply reflect the differences among populations in attractiveness to $C$. rubecula. Moreover, no single chemical matched the differences in attractiveness.

The importance of specific HIPVs in natural enemy attraction traditionally has focused on terpenes, fatty acid derivatives (especially those produced by the lipoxygenase pathway), and products from the phenylalanine lyase (PAL) pathway (Ozawa et al. 2000; Schnee et al. 2006; Shiojiri et al. 2006a; Halitschke et al. 2008; Zhang et al. 2009). Here, we showed that the terpenes $(E)$ - $\beta$-ocimene and DMNT may play a limited role in $C$. rubecula attraction. For example, exposure to $(E)$ - $\beta$-ocimene elicits a response in the antennae of $C$. rubecula (Smid et al. 2002) and (E)- $\beta$-ocimene and DMNT also are produced by Brussels sprout plants in response to exogenous treatment with JA (Bruinsma et al. 2009). Nevertheless, here, C. rubecula did not discriminate between JA-treated wild cabbage plants, suggesting that compounds independent of the lipoxygenase pathway are responsible for the differentiation in volatile emissions and consequent attraction of the parasitoid.

Breakdown products of GS represent another important group of volatiles that could be used by parasitoids to detect hosts that are specialist herbivores of brassicaceous plants. Species in this plant family all biosynthesize GS (Halkier and Gershenzon 2006). Glucosinolates function as direct defensive compounds against a range of attackers that include insect herbivores (Rask et al. 2000; Hopkins et al. 2009). Deterrence activity only emerges after tissue rupture, e.g., by caterpillar feeding, and concomitant release of the enzyme myrosinase, which is stored in specialized cells. This enzyme catalyzes the conversion of GS into toxic hydrolysis products of which many are volatile (Halkier and Gershenzon 2006). Glucosinolate concentrations are generally much lower in cultivated brassicaceous plant species compared to the levels found in wild conspecifics because of the effects of directional selection in plant breeding programs (Gols et al. 2008b; Harvey et al. 2011). 
Fig. 6 PLS-DA comparison of quantities of volatile compounds produced by the wild $\mathrm{OH}$ and WIN populations of Brassica oleracea with the score plot of the samples (a) and loadings of the volatile variables (b). Percentage of the explained variance is given in brackets. The PLS-DA resulted in a model with 1 significant component: $R^{2} \mathrm{X}=0.34, R^{2} \mathrm{Y}=0.83 Q^{2}=0.70$ (the second axis is shown for representational purposes). For compound identity see Table 1
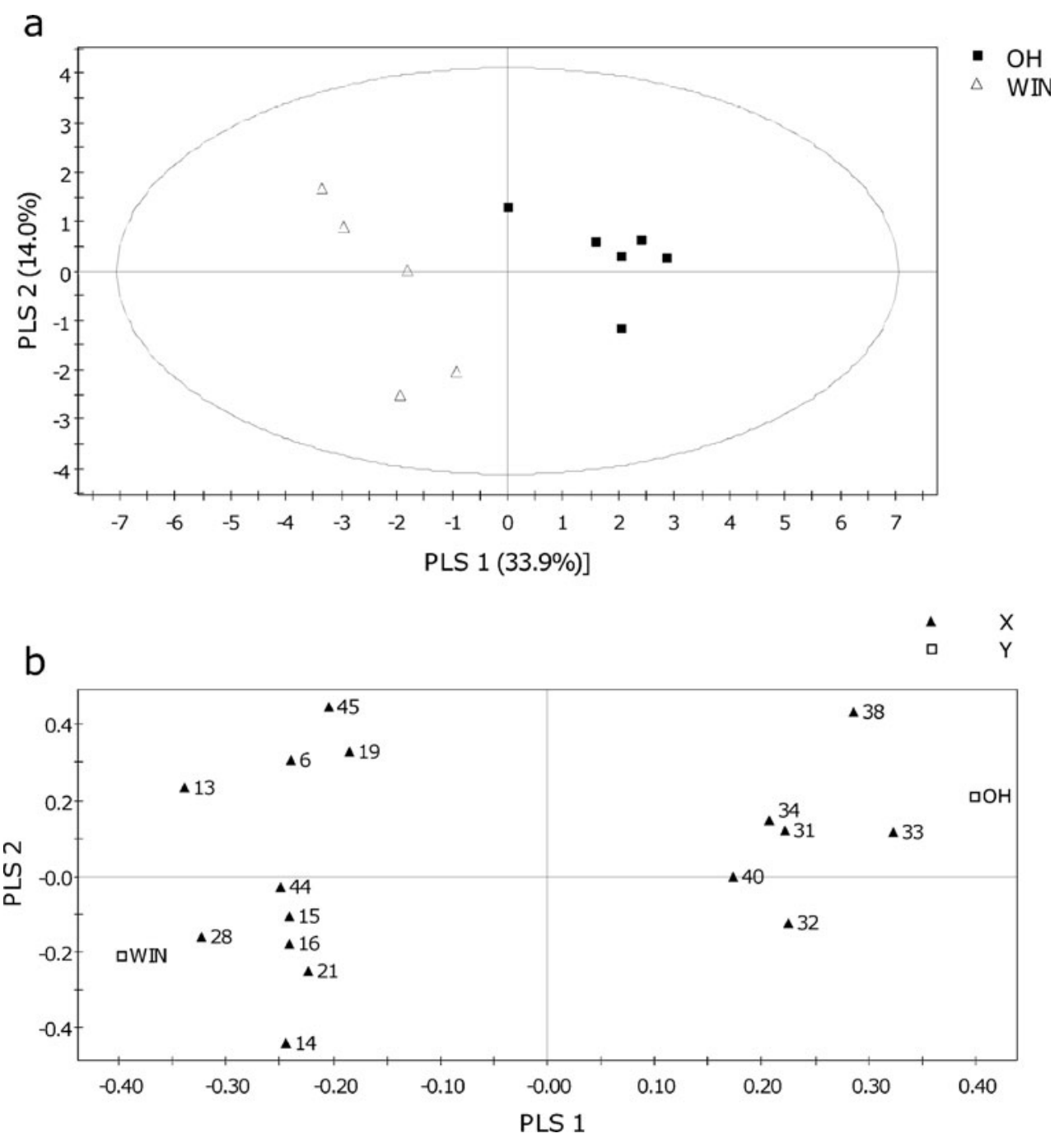

Importantly, the effects of volatile GS breakdown products on parasitoid attraction frequently have been overlooked because these products are not detected in HIPV blends emitted by cultivated brassicaceous plants (Geervliet et al. 1997; Bukovinszky et al. 2005), whereas they are emitted in large quantities by wild species in this family following herbivory (Gols et al. 2008c, 2009). Here, we also found that volatile GS breakdown products, i.e., but-3-enyl isothiocyanate and prop-2-enyl isothiocyanate, were produced only by wild cabbage plants. Thus far, few studies have investigated the attractiveness of GS hydrolysis products to parasitoids (Bradburne and Mithen 2000; Blande et al. 2007). The parasitoid Diaeretiella rapae, which attacks the Brassica-feeding aphid Brevicoryne brassicae, is not only attracted to plants producing isothiocyanates, but female wasps of this species even discriminate between plants producing different isothiocyanates (Bradburne and Mithen 2000). Interestingly, KIM plants had the lowest emission rates of these compounds, suggesting that other cues determine the relative attractiveness to $C$. rubecula of plants from the wild populations.
Volatile emissions are known to vary considerably in quality and quantity, both within and among brassicaceous plant species (Bukovinszky et al. 2005; Gols et al. 2008c). Here, we demonstrated that the volatile blend emitted by KIM plants differed clearly from those emitted by WIN and $\mathrm{OH}$ plants, whereas KIM plants were of intermediate attractiveness to $C$. rubecula in the flight bioassay. Our result suggests that the response of $C$. rubecula is based on far more complex choice rules than simple responses to a subset of specific volatile compounds. Several studies have reported that insect natural enemies are able to detect modifications in the emission of terpenes and fatty acid derivatives (Kappers et al. 2005; Shiojiri et al. 2006b; Halitschke et al. 2008). In addition, the emission of repellent compounds may decrease the attractiveness of a volatile blend (e.g., Soler et al. 2007). Combinations of qualitative and quantitative characteristics of the volatile blend could determine the relative importance of specific volatiles in an HIPV blend. Moreover, foraging choices by a parasitoid like $C$. rubecula may not be rigid. For example, pre-adult learning may influence the 'naïve' response of 
Fig. 7 PLS-DA comparison of quantities of volatile compounds produced by the wild $\mathrm{OH}$ population and the CYR cultivar of Brassica oleracea with the score plot of the samples (a) and loadings of the volatile variables (b). Percentage of the explained variance is given in brackets. The PLS-DA resulted in a model with 2 significant components: $R^{2} \mathrm{X}=0.85, R^{2} \mathrm{Y}=0.97$ $Q^{2}=0.90$. For compound identity see Table 1

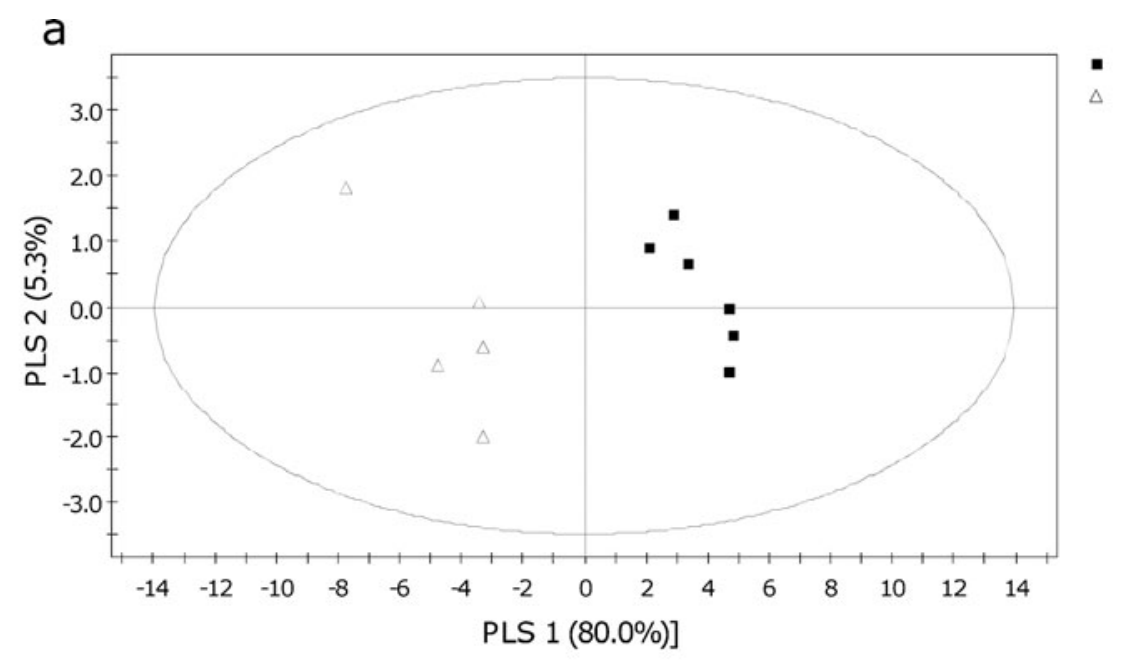

$\mathrm{OH}$ CYR

\section{b}

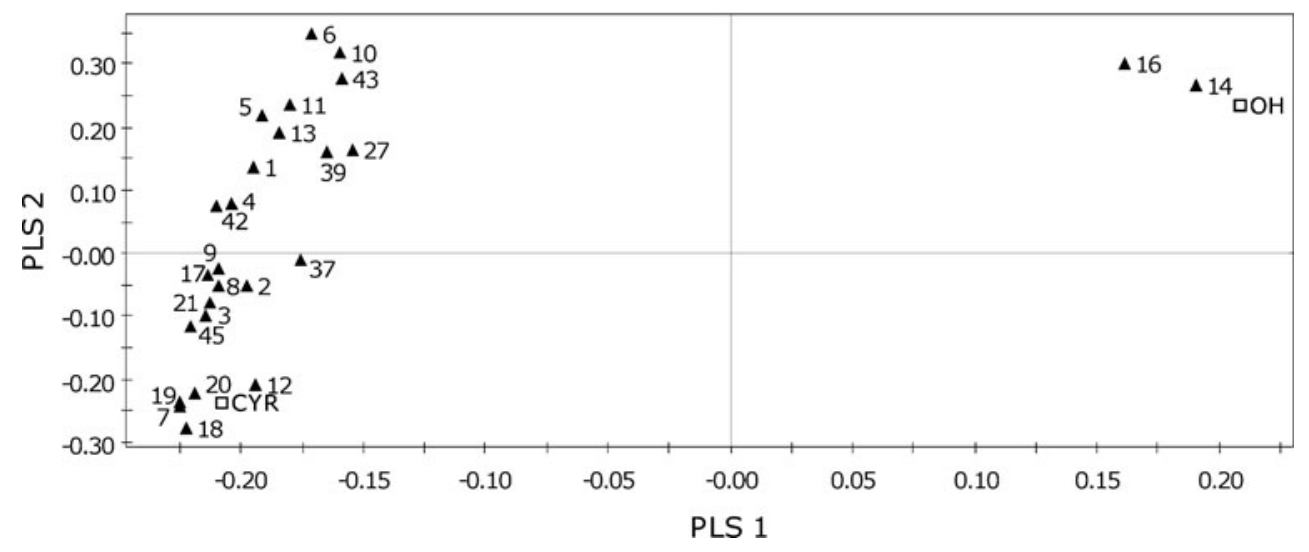

adult wasps (Gandolfi et al. 2003). Remarkably, $C$. rubecula preferred wild $\mathrm{OH}$ over cultivated CYR plants despite their rearing history on the latter plant strain. This result suggests that the naïve response to volatiles emitted by wild plants is conserved. For example, isothiocyanates which were only produced by the wild cabbage plants could be the key components in separating wild from cultivated cabbage; other compounds such as terpenes may facilitate differential attraction among the wild populations.

In nature, $C$. rubecula has to search for hosts that can occur on different plant species in the Brassicaceae. Pieris rapae has two to three generations across much of its natural range in central Europe, and most of its food plants are annuals or biennials with short growing seasons. Many of these plants exhibit discrete periods of growth, with some species only occurring early in spring, others in late spring, and still others in summer (Fig. 2). This means that different generations of $C$. rubecula are likely to develop in hosts feeding on different food plant species that emit dramatically different HIPV blends (Bukovinszky et al. 2005; Gols et al. 2008c). Almost all studies of plant- herbivore-parasitoid interactions associated with B. oleracea have only used cultivars (Gols and Harvey 2009). Cues, such as volatile GS breakdown products, which are phylogenetically conserved, may be more reliable for naïve parasitoids than more general plant related cues (terpenes, fatty acid derivatives) (Dudareva et al. 2004). Explaining how parasitoids use local information in finding hosts over different spatial scales in natural environments has been little studied. Our findings suggest that it will be worthwhile to investigate how differences in HIPV blends among populations of wild Brassica species may structure local host-parasitoid communities, and how artificial selection by domestication impacts these processes.

To summarize, we have shown that there is considerable within and between population variability in volatile profiles of wild and cultivated cabbage plants. Moreover, $C$. rubecula females discriminated among three wild $B$. oleracea populations, as well as between one of the wild populations and a cabbage cultivar on which the parasitoid has been reared for many generations. In parasitoid species whose hosts may feed on different food plants, 
selection may favor a flexible response to plant infochemicals when the variation among the blends emitted by different potential food-plant species is high. Although in laboratory studies it has been demonstrated that parasitoids like C. rubecula can discriminate between blends that differ in the emission of a single or a few compounds, these results are not conclusive in determining which specific volatiles are important for host plant location in nature. Moreover, the focus of these studies is phytocentric, i.e., unraveling the mechanisms underlying the biosynthesis of these compounds in planta, and conclusions are often based on results using cultivated plant species where there is little within-strain variation in the expression of traits like direct and indirect defense (van der Meijden and Klinkhamer 2000; Allison and Hare 2009; Kessler and Heil 2011). As shown here, HIPV blends emitted by cultivated plants whose chemistry has been modified in plant breeding programs may not resemble the volatile blends that are emitted by wild plant species with which the parasitoid has coevolved. Most importantly, these studies to a large extent ignore the biology and ecology of co-evolved multitrophic interactions involving wild plants, herbivores and parasitoids.

Acknowledgements We thank A. Gidding, F. van Aggelen, and L. Westerd for rearing of the insects, Unifarm for rearing of the plants. The help by Cees Hordijk (NIOO) who run the GC-MS analyses of the volatile samples is acknowledged.

Open Access This article is distributed under the terms of the Creative Commons Attribution Noncommercial License which permits any noncommercial use, distribution, and reproduction in any medium, provided the original author(s) and source are credited.

\section{References}

Allison, J. D., and HARE, J. D. 2009. Learned and naive natural enemy responses and the interpretation of volatile organic compounds as cues or signals. New Phytol. 184:768-782.

ARIMURA, G.-I., MatsUI, K., and TAKABAYASHI, J. 2009. Chemical and molecular ecology of herbivore-induced plant volatiles: proximate factors and their ultimate functions. Plant Cell Physiol. 50:911-923.

BERENBAUM, M. R., and ZANGERL, A. R. 2008. Facing the future of plant-insect interaction research: Le Retour a la "Raison d'Etre". Plant Physiol. 146:804-811.

Blande, J. D., PicketT, J. A., and Poppy, G. M. 2007. A comparison of semiochemically mediated interactions involving specialist and generalist Brassica-feeding aphids and the braconid parasitoid Diaeretiella rapae. J. Chem. Ecol. 33:767-779.

BradBurNe, R. P., and Mithen, R. 2000. Glucosinolate genetics and the attraction of the aphid parasitoid Diaeretiella rapae to Brassica. Proc. R. Soc. Lond. B Biol. Sci. 267:89-95.

Bruinsma, M., Posthumus, M. A., Mumm, R., Mueller, M. J., VAN LOON, J. J. A., and Dicke, M. 2009. Jasmonic acid-induced volatiles of Brassica oleracea attract parasitoids: effects of time and dose, and comparison with induction by herbivores. J. Exp. Bot. 60:2575-2587.
Bukovinszky, T., Gols, R., Posthumus, M. A., Vet, L. E. M., and VAN LENTEREN, J. C. 2005. Variation in plant volatiles and attraction of the parasitoid Diadegma semiclausum (Hellen). $J$. Chem. Ecol. 31:461-480.

De Moraes, C. M., Lewis, W. J., Pare, P. W., Alborn, H. T., and TuMLINSON, J. H. 1998. Herbivore-infested plants selectively attract parasitoids. Nature 393:570-573.

De Vos, M., Van Oosten, V. R., Van Poecke, R. M. P., Van Pelt, J. A., Pozo, M. J., Mueller, M. J., Buchala, A. J., Metraux, J. P., VAN LOON, L. C., DicKE, M., et al. 2005. Signal signature and transcriptome changes of Arabidopsis during pathogen and insect attack. Mol. Plant-Microbe Interact. 18:923-937.

DiCKE, M., and BALDWIN, I. T. 2010. The evolutionary context for herbivore-induced plant volatiles: beyond the 'cry for help'. Trends Plant Sci. 15:167-175.

Dicke, M., Van Beek, T. A., Posthumus, M. A., Ben Dom, N., Van BOKHOVEN, H., and DE GROOT, A. E. 1990. Isolation and identification of volatile kairomone that affects acarine predatorprey interactions: involvement of host plant in its production. $J$. Chem. Ecol. 16:381-396.

Dicke, M., Gols, R., Ludeking, D., and Posthumus, M. A. 1999. Jasmonic acid and herbivory differentially induce carnivoreattracting plant volatiles in lima bean plants. J. Chem. Ecol. 25:1907-1922.

Dudareva, N., Pichersky, E., and Gershenzon, J. 2004. Biochemistry of plant volatiles. Plant Physiol. 135:1893-1902.

Eriksson, L., Johansson, E., KetTaneh-Wold, N., TrygG, J., Wikstrom, C., and Wold, S. 2006. Multi- and Megavariate Data Analysis. Part 1: Basic Principles and Applications. Umetrics AB, Umeå, Sweden.

Gandolfi, M., Mattiacci, L., and Dorn, S. 2003. Preimaginal learning determines adult response to chemical stimuli in a parasitic wasp. Proc. R. Soc. Lond. B Biol. Sci. 270:2623-2629.

GeErVliet, J. B. F., Vet, L. E. M., and Dicke, M. 1994. Volatiles from damaged plants as major cues in long-range host-searching by the specialist parasitoid Cotesia rubecula. Entomol. Exp. Appl. 73:289-297.

Geervliet, J. B. F., Posthumus, M. A., Vet, L. E. M., and Dicke, M. 1997. Comparative analysis of headspace volatiles from different caterpillar-infested or uninfested food plants of Pieris species. J. Chem. Ecol. 23:2935-2954.

Gols, R., and Harvey, J. A. 2009. Plant-mediated effects in the Brassicaceae on the performance and behaviour of parasitoids. Phytochem. Reviews 8:187-206.

Gols, R., BukovinszKY, T., VAn Dam, N. M., Dicke, M., Bullock, J. M., and HarveY, J. A. 2008a. Performance of generalist and specialist herbivores and their endoparasitoids differs on cultivated and wild Brassica populations. J. Chem. Ecol. 34:132-143.

Gols, R., WAgENAAR, R., BUKOVINSZKY, T., VAN DAM, N. M., DickE, M., Bullock, J. M., and HARVEY, J. A. 2008b. Genetic variation in defense chemistry in wild cabbages affects herbivores and their endoparasitoids. Ecology 89:1616-1626.

Gols, R., Witjes, L. M. A., Van Loon, J. J. A., Posthumus, M. A., Dicke, M., and HARVEY, J. A. 2008c. The effect of direct and indirect defenses in two wild brassicaceous plant species on a specialist herbivore and its gregarious endoparasitoid. Entomol. Exp. Appl. 128:99-108.

Gols, R., Van Dam, N. M., RaAijmakers, C. E., Dicke, M., and HARVEY, J. A. 2009. Are population differences in plant quality reflected in the preference and performance of two endoparasitoid wasps? Oikos 118:733-743.

Gouinguene, S., Pickett, J. A., Wadhams, L. J., Birkett, M. A., and Turlings, T. C. J. 2005. Antennal electrophysiological responses of three parasitic wasps to caterpillar-induced volatiles from maize (Zea mays mays), cotton (Gossypium herbaceum), and cowpea (Vigna unguiculata). J. Chem. Ecol. 31:1023-1038. 
Halitschke, R., Stenberg, J. A., Kessler, D., Kessler, A., and BALDWIN, I. T. 2008. Shared signals - 'alarm calls' from plants increase apparency to herbivores and their enemies in nature. Ecol. Lett. 11:24-34.

HALKIER, B. A., and GerShENZON, J. 2006. Biology and biochemistry of glucosinolates. Annu. Rev. Plant Biol. 57:303-333.

Harvey, J. A., Gols, R., WagenaAr, R., and Bezemer, T. M. 2007. Development of an insect herbivore and its pupal parasitoid reflect differences in direct plant defense. J. Chem. Ecol. 33:1556-1569.

Harvey, J. A., VAn Dam, N. M., RaAijmakers, C. E., Bullock, J. M., and GoLs, R. 2011. Tri-trophic effects of inter- and intrapopulation variation in defence chemistry of wild cabbage (Brassica oleracea). Oecologia 166:421-431.

HOPKINS, R. J., VAN DAM, N. M., and VAN LOON, J. J. A. 2009. Role of glucosinolates in insect-plant relationships and multitrophic interactions. Annu. Rev. Entomol. 54:57-83.

KAPPERS, I. F., AHARONI, A., VAN HERPEN, T. W. J. M., LUCKERHOFF, L. L. P., Dicke, M., and Bouwmeester, H. J. 2005. Genetic engineering of terpenoid metabolism attracts, bodyguards to Arabidopsis. Science 309:2070-2072.

Kessler, A., and HeIL, M. 2011. The multiple faces of indirect defences and their agents of natural selection. Funct. Ecol. 25:348-357.

Köllner, T. G., Held, M., LenK, C., Hiltpold, I., Turlings, T. C. J., Gershenzon, J., and Degenhardt, J. 2008. A maize $(E)$ beta-caryophyllene synthase implicated in indirect defense responses against herbivores is not expressed in most American maize varieties. Plant Cell 20:482-494.

Mumm, R., Posthumus, M. A., and Dicke, M. 2008. Significance of terpenoids in induced indirect plant defence against herbivorous arthropods. Plant Cell Environ. 31:575-585.

OzaWa, R., Arimura, G., TAKabaYashi, J., Shimoda, T., and NisHIOKA, T. 2000. Involvement of jasmonate- and salicylaterelated signaling pathways for the production of specific herbivore-induced volatiles in plants. Plant Cell Physiol. 41:391-398.

Rask, L., ANDreasson, E., Ekbom, B., ERIKSSON, S., PontopPidan, B., and MEIJER, J. 2000. Myrosinase: gene family evolution and herbivore defense in Brassicaceae. Plant Mol. Biol. 42:93-113.

Rasmann, S., Kollner, T. G., Degenhardt, J., Hiltpold, I., Toepfer, S., Kuhlmann, U., Gershenzon, J., and Turlings, T. C. J. 2005. Recruitment of entomopathogenic nematodes by insect-damaged maize roots. Nature 434:732-737.

Reymond, P., Bodenhausen, N., Van Poecke, R. M. P., KrishnaMURTHY, V., DICKE, M., and FARMER, E. E. 2004. A conserved transcript pattern in response to a specialist and a generalist herbivore. Plant Cell 16:3132-3147.

SABElis, M. W., and VAN DE BAAN, H. E. 1983. Location of distant spider mite colonies by Phytoseiid predators: demonstration of specific kairomones emitted by Tetranychus urticae and Panonychus ulmi. Entomol. Exp. Appl. 33:303-314.
Schnee, C., Kollner, T. G., Held, M., Turlings, T. C. J., GERShEnZON, J., and DEGENHARDT, J. 2006. The products of a single maize sesquiterpene synthase form a volatile defense signal that attracts natural enemies of maize herbivores. Proc. Natl. Acad. Sci. U. S. A. 103:1129-1134.

Shiojiri, K., Kishimoto, K., OzaWa, R., KugimiYa, S., Urashimo, S., Arimura, G., Horiuchi, J., Nishioka, T., Matsui, K., and TAKABAYASHI, J. 2006a. Changing green leaf volatile biosynthesis in plants: an approach for improving plant resistance against both herbivores and pathogens. Proc. Natl. Acad. Sci. U. S. A. 103:16672-16676.

Shiojiri, K., OzaWa, R., Matsui, K., Kishimoto, K., KugimiYa, S., and TAKABAYASHI, J. 2006b. Role of the lipoxygenase/lyase pathway of host-food plants in the host searching behavior of two parasitoid species, Cotesia glomerata and Cotesia plutellae. J. Chem. Ecol. 32:969-979.

Smid, H. A., Van Loon, J. J. A., Posthumus, M. A., and Vet, L. E. M. 2002. GC-EAG-analysis of volatiles from Brussels sprouts plants damaged by two species of Pieris caterpillars: olfactory receptive range of a specialist and a generalist parasitoid wasp species. Chemoecology 12:169-176.

Soler, R., Harvey, J. A., Kamp, A. F. D., Vet, L. E. M., Van Der Putten, W. H., VAn Dam, N. M., Stuefer, J. F., Gols, R., HordiJK, C. A., and BEZEMER, T. M. 2007. Root herbivores influence the behaviour of an aboveground parasitoid through changes in plant-volatile signals. Oikos 116:367-376.

SteIDLE, J. L. M., and VAN LOON, J. J. A. 2003. Dietary specialization and infochemical use in carnivorous arthropods: testing a concept. Entomol. Exp. Appl. 108:133-148.

THALER, J. S. 1999. Jasmonate-inducible plant defences cause increased parasitism of herbivores. Nature 399:686-688.

TURLINGS, T. C. J., and WÄCKERS, F. 2004. Recruitment of predators and parasitoids by herbivore-injured plants, pp. $21-75$, in R. T. Carde and J. G. Millar (eds.). Advances in Insect Chemical Ecology. Cambridge University Press, Cambridge.

Turlings, T. C. J., Loughrin, J. H., Mccall, P. J., Rose, U. S. R., Lewis, W. J., and Tumlinson, J. H. 1995. How caterpillardamaged plants protect themselves by attracting parasitic wasps. Proc. Natl. Acad. Sci. U. S. A. 92:4169-4174.

Van Der Meidden, E., and Klinkhamer, P. G. L. 2000. Conflicting interests of plants and the natural enemies of herbivores. Oikos 89:202-208

VET, L. E. M., and DiCKE, M. 1992. Ecology of infochemical use by natural enemies in a tritrophic context. Annu. Rev. Entomol. 37:141-172.

WichmanN, M. C., AleXander, M. J., Hails, R. S., and Bullock, J. M. 2008. Historical distribution and regional dynamics of two Brassica species. Ecography 31:673-684.

Zhang, P. J., ZHENG, S. J., VAN LOON, J. J. A., BOLAND, W., DaVID, A., Mumm, R., and DicKe, M. 2009. Whiteflies interfere with indirect plant defense against spider mites in Lima bean. Proc. Natl. Acad. Sci. U. S. A. 106:21202-21207. 